\title{
Some Recent Work on the Light of the Night Sky. ${ }^{1}$ By LoRd RaYLeigh, F.R.S.
}

Periodicities.

$\mathrm{A}^{\mathrm{N}}$ annual periodicity was early suspected in my A own observations in England. At the time of writing, observations lasting over five years are available, so far as the auroral component is concerned. To examine impartially whether or not an annual variation is present, the observations night sky during this period, if such an influence exists at all.

To eliminate any effect of the annual periodicity just discussed, it is necessary to compare the intensity in successive years at the same season. If we look at any given column in the table (say, October) we find a tendency to increase with time, though this tendency is not strong enough always to assert itself against the irregularities after the lapse of a single year. But in every one of the nine columns the last entry is substantially higher than the first. If the variations when cleared of the annual periodicity were quite unsystematic, the chance of this occurring would be only $2^{-9}$, or 1 in 512 . of each calendar month (say, November 1926) are averaged, and the mean is adopted as representative of that particular month, without further reference to the data for individual nights.

The individual seasons and the mean'are plotted in Fig. 2.

Although the results are not numerous enough to give complete statistical regularity, yet I think it is difficult to resist the indications of a definite annual period. The great fall of intensity usually occurs between November and December. In each of the four complete observing seasons (August to April) the mean of all months before this date is much greater than the mean after it. This fall must have its counterpart in a recovery, which would naturally be taken to occur six months later, that is, between May and June.

No observations can be made at that season owing to residual daylight. But in every one of the five cases available, a considerable recovery has occurred at some time between April and August, in the interval when residual daylight prevents observations.

Special attention is directed to the mean curve at the bottom of Fig. 2, which sums up the evidence for annual periodicity. The amplitude of annual variation indicated is about 2 units, or a factor of 1.6. The subordinate maximum in March may be due to coincidence of irregular variations, but it is well to keep an open mind on this point, particularly in view of certain magnetic periodicities.

Turning now to a second question, that of variation in the cycle of the sunspots, it is to be noted that the observations begin at about the time of sunspot minimum in 1923, and that according to present expectation the maximum will be reached in the present year, 1928. By analogy with other phenomena known to depend on the sunspot cycle, we should anticipate an increase in the light of the

2 Continued from p. 317.

No. 3071 , VoL. 122]
For greater statistical regularity, we may take the mean of all the months in a given observing season, or in a given year. To include observations taken in the spring of 1923 and in the present uncompleted observing season, the latter course is adopted.

The result is shown graphically in Fig. 3. The mean annual increase is 0.3 unit, representing a factor of 1.07 . Thus the results clearly indicate a general yearly increase of the intensity during practically the whole period of observation, relative to the uranium standard. This could be explained away if we assumed a slow loss of brightness in the standard, but there are reasons which seem adequate for rejecting this explanation.

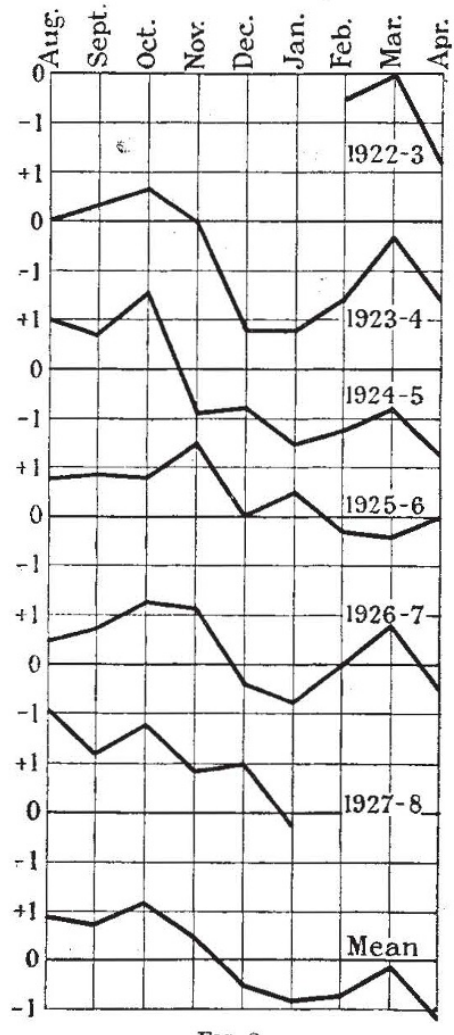

FIG. 2.
Returning to the question of annual periodicity, it seems probable that this depends on the sun's motion in declination. If so, the effect should be negligible at the equator, and should show itself in the opposite 
phase in the southern hemisphere. There is some evidence from the available data that this is in fact the case.

\section{Polar Aurora.}

It is important to distinguish between the polar aurora occurring typically in the auroral zones, and the non-polar aurora occurring all over the earth. Both have the green line $\lambda 5578$, which has been shown by the work of McLennan and his colleagues to be due to oxygen, as the strongest feature of the visual spectrum. It may seem an arbitrary procedure to distinguish two separate phenomena when there is so much in common, and I know from correspondence and otherwise that some scientific men are unwilling to admit it. Nevertheless, after further experience and study, I am more than ever convinced that it is necessary.

The grounds on which this distinction was originally made were that the nitrogen bands (negative bands) occur only in the polar aurora; that the polar aurora has a distinctive distribution in latitude which the other has not; that the polar aurora often shows distinctive forms such as ares and draperies, whereas the non-polar aurora is uniform; while, finally, the polar aurora varies

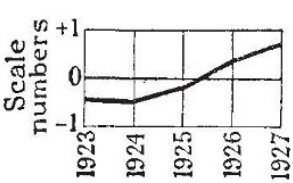

FIG. 3. enormously in intensity in the course of a few minutes, whereas the non-polar aurora is often sensibly constant for days. I wish now to discuss the subject from the viewpoint of intensity measurements.

We find, in the majority of stations, where ' auroral displays' rarely, if ever, occur, that the range of intensity observed through the auroral filter, which I take as a measure of the intensity of the green line, has a fairly definite mean value of about $0 \cdot 4$ on my scale, with a standard deviation of $\mathbf{1} \cdot 0$. It is true that this intensity is subject to a yearly, and probably also to an 11-yearly, variation. But these variations are comparatively slight, and for the present purpose may be ignored. Lerwick (Shetland), Victoria (British Columbia), and Kingston (Ontario) are stations where auroral displays are comparatively common. At the Cape, or at Canberra, or Hawaii, they are practically unknown. The case of England is intermediate. Auroral displays occur occasionally, though not often.

Let us consider what happens in this intermediate case, where the statistical issue can be most easily presented. In the year 1926 my observations in England on 75 nights, in the absence of an auroral display, give for the auroral intensity :

$$
\begin{aligned}
& \text { Range . . . . }-2 \cdot 2 \text { to }+3 \cdot 0 \\
& \text { Mean value . . . + }+0 \cdot 2 \\
& \text { Standard deviation . . } \quad 1 \cdot 1
\end{aligned}
$$

Now only one auroral display was observed, when it was found that

$$
\begin{array}{ll}
\text { Auroral display gave } . & +16 \cdot 0 \\
\text { Deviation from the mean }: & +15 \cdot 8
\end{array}
$$

thus giving an isolated deviation of no less than
14.4 times the standard. As is well known in all ordinary cases of statistical distribution, values three times the standard are nearly the highest that occur. A value $\mathbf{1 4} \cdot 4$ times the standard is fantastic, and shows that we are attempting to classify in the same scheme values that are not properly comparable at all. In the case of barometric variations at sea-level, such a deviation would mean a barometric height of about 34.7 in.! This comparison shows that we must class auroral displays as quite a distinct set of phenomena.

As is well known, the visual light of an auroral display consists for the most part of the visual green line, and accordingly it is this component (auroral green) which is most strongly reinforced

\begin{tabular}{|c|c|c|c|c|}
\hline Place. & Date. & Red. & A uroral. & Blue. \\
\hline $\begin{array}{l}\text { Victoria : } \\
\text { Lingston: } \\
\text { Lerwick : }\end{array}$ & $\begin{array}{l}\text { Sept. } 20,1925 \\
\text { Mar. } 5,1926 \\
\text { Jan. } 13,1926\end{array}$ & $\begin{array}{l}+2 \cdot 6 \\
+5 \cdot 9 \\
+2 \cdot 1\end{array}$ & $\begin{array}{l}+13 \cdot 5 \\
+13 \cdot 0 \\
+16 \cdot 7\end{array}$ & $\begin{array}{l}+13.0 \\
+13.4 \\
+11.9\end{array}$ \\
\hline
\end{tabular}
when a bright display is in progress. It is always found, however, that the red and blue components are strengthened as well. The following typical examples may be given:

These may be compared with the normal values in the absence of a display, given earlier in this paper. The increase of intensity in the blue part of the spectrum is probably attributable in the main to the negative bands of nitrogen. The increase in the red is less marked. It may be due in part to the known red line of the aurora, but I believe more to an (apparently) continuous background, which may, of course, be an unresolved band spectrum.

\section{Conclusion.}

In conclusion, I must emphasise that much of the work of this paper, though necessarily organised and edited from one centre, would have been impossible without the friendly and generous cooperation of the workers whose names have already been recited. They have given their time and trouble without stint.

As regards the future, it has been borne in upon me that greater accuracy of photometric measurement is a chief requisite. This will be obtained by means of a photoelectric cell. Most of the difficulties have been overcome, and preliminary observations have been in progress for some months past. I have been able to follow the changes of intensity from hour to hour on clear nights ; some evidence has been found suggesting a diurnal periodicity. The observed intensity nearly always increases between nightfall and midnight, beyond which the observations have not usually been carried. ${ }^{2}$ Although no correlation has been found

${ }^{2}$ On June 28 , Prof. J. C. Melennan arrived at a similar conclusion as to the course of change during the night in his Bakerian Lecture delivered before the Royal Society. I merely add this note to make it clear that Prof. MeLennan's conclusion and my own were reached cated to Prof. Chapman for publication on June 18 .

(Continued on p. 373.)

No. 3071 , VoL. 122] 
in the irregular variations at distant stations, there must be correlation at stations close together, and it is important to determine limits of distance. By the photoelectric method this should be comparatively quick and easy.

\section{BiBLIOGRAPHY.}

The work here described is discussed somewhat more fully in Proc. Roy. Soc. A, vol. 119, p. 11,
1928. The figures are here reproduced by kind permission of the Society.

See also on some points earlier papers-Proc. Roy. Soc. A, vol. 106, p. 117 (1924), and Proc. Roy. Soc. A, vol. 109, p. 428 (1925).

The results of these earlier papers are, however, in part superseded.

A paper on Visual Observations of the Aurora Line in the Night Sky appears in Gerlands Beiträge zur Geophysik, May 1928.

\section{Oceanographic Observations between Greenland and North America.}

\section{By Donald J. Matthews.}

\section{$\mathrm{T}$} HE history of the exploration of the seas between Greenland and America begins in the year 982, when Erik the Red founded on the south-west coast of Greenland the Norwegian colonies which were abandoned about the end of the fourteenth century. To oceanographers, the interest of this episode lies in a suggestion by Otto Pettersson that such voyages could not have been made in the open ships of the Norsemen unless the ice conditions had been much more favourable than they are now, and that the colonies were eventually abandoned because the climate had become more severe. The second stage in the exploration was the series of attempts to find a Northwest Passage, which came to an end with the discovery of Baffin Bay in 1616, and the third brings us down to the present time and includes the whaling voyages, the Danish voyages of discovery along the Greenland coast, and modern Arctic exploration. The reports of the ice masters contained a great store of information as to the general set of the currents and the distribution of icebergs and sea ice, but little else of oceanographical value, and in particular they throw no light on the cause of the great variation from year to year in the amount of ice which drifts southwards to the trans-Atlantic traffic lanes.

The circulation of the water is fairly simple. The East Greenland Current flows south and west to Cape Farewell, round which it turns to the north-west under the directing force of the earth's rotation and the density gradient across the coastal fringe of lighter water. It then becomes the West Greenland Current and flows northwards, probably as far as Melville Bay; according to some oceanographers, however, it does not penetrate beyond Disko Bay, and the northerly coastal current in Melville Bay is of the nature of an eddy. No east coast bergs are found on the west coast north of Julianehaab, about 100 sea miles beyond Cape Farewell; and in the Godthaab region, in about $65^{\circ} \mathrm{N}$. lat., the cold current comes in contact with a warmer salter Atlantic current, in which the last of the sea ice melts. There appears to be a tendency for the current to spread westwards on the surface in these latitudes, but it carries no ice with it. Much less is any ice carried southwestwards from Cape Farewell to Newfoundland by a direct extension of the East Greenland Current, in the way shown on some of the older charts, with complete neglect of the necessary effect of the earth's rotation.

In Baffin Bay there is a northerly set on the east side in Melville Bay with many bergs, and westwards of this two great southerly drifts of heavy ice which are derived from Smith Sound, the western Sounds, and from Melville Bay, which are known as the Middle Ice and the West Ice. Between them, at the head of Baffin Bay, lies one of the most interesting features of these regions, an open space called the North Water, said never to freeze over, and generally attributed to a current of warm salt Atlantic water welling up from below. The Middle Ice and the West Ice unite at the northern entrance to Davis Strait, and as the Labrador Current flow south and east along the continental shelf of the Labrador coast as far as the Tail of the Grand Banks.

Little is known of the oceanography of these waters. The Scotia and the Chance have shown that the current on the Labrador coast is confined to the shallow water of the continental shelf, and that to the eastward of it lies warmer and salter Atlantic water in which the lines of equal density are horizontal, as if the water were at rest, at least so far as density currents are involved. This is somewhat remarkable, since there must be a continual movement northwards to compensate for the water removed on the outer edge of the Labrador Current, and in any event it is known that this water, or at least a similar water, dives under the fresher and colder surface layer in about the latitude of Cape Farewell and flows over the ridge in Davis Strait as undercurrent at a depth of 125 metres. In Disko Bay it is found at 200 metres, and at 250 metres in Melville Bay. In the north of Baffin Bay it meets the rising bottom at the entrance to Smith Sound, and is forced upwards to form the North Water and feed the Middle and West Ice. The permanent existence of such a warm layer between two colder ones necessitates a permanent northward flow from the open Atlantic.

The currents described account for the general trend of the movements of the ice but do not explain their changes. In 1906, Mecking published a discussion of the material then available from the years 1888 to 1896 . According to his results, the bergs are for the most part formed in the Disko region, on the west coast of Greenland

$$
\text { No. 3071, VoL. 122] }
$$

